\title{
Research on the Tourism Scenic Spot E-Business Integration
}

\section{Framework}

\author{
Tao $\mathrm{Hu}^{1, \mathrm{a}^{*}}$, Yalin Zhang ${ }^{1}$, Shangkui Zheng ${ }^{1}$, Yetong Wang ${ }^{1}$, \\ Yang Cao ${ }^{1}$, Lin Qiao ${ }^{1}$ \\ ${ }^{1}$ Hainan University, Haikou,China \\ a869310131@qq.com
}

Key words: Tourism Scenic Spot, E-Business, Integration Framework

Abstract. Although scenic spots make the use of various different technology in mangy business departments such as human resources management, inventory(warehouse) management, sales management, manufacturing workshop, financial department, office automation and so on. However, it is a big problem how to construct an E-Business Service Platform to make these components work in coordination. Besides, also it is important to connect the intranet system with outside systems. For examples, e-commerce, tourism supply system, EDI, CRM. In this paper, it is put out the e-business service platform to fulfill this mission. The portal site, tourism statistics and analysis, e-commerce, tourism resources acquisition, 12301, electronic document exchange system, industry finance system could exchange their possessed data. On the other hand, the integration technology is also presented in the study. business Documentation, business search, authorization, responsibility identification, pay and settlement, credit collection, authentication, RFID, middleware, Heterogeneous systems interfaces, content analysis, rule engine, workflow engine are also mentioned in the research. The integration framework also contains the solution of putting these important technologies work well.

\section{Introduction}

OLAY is a theoretical model for the growth of information technology (IT) in a business or similar organization. It was developed by Richard L. Nolan during the 1970s, and published by him in the Harvard Business Review[1-3].

Nowadays, many tourism scenic spots are between the stages of Stage III - Control

And Stage IV - Integration.There is use of database and communications, often with negative general management reaction. And also there is formal planning and control within data processing. However, data administration is not introduced and the applications portfolio is not integrated into the organization. Each business department has its own data format, and they could not share the data from different data sources[4,5]. For the enterprise, it is the key to integrate the data and to make the whole decision for its rapid developing. It is important to make the data from human resources management, inventory(warehouse) management, sales management, manufacturing workshop, financial department etc. Exchange[6-8].

E-Business Service Platform will be given first, which connect the industry finance system, electronic document exchange system, tourism industry management, guide system, 12301 system, tourism resources acquisition, tourism statistics, research projects management, e-commerce and portal sits etc. And then Technology Integration is introduced for business Documentation, business 
search, authorization, responsibility identification, pay and settlement, credit collection, authentication, RFID, middleware, heterogeneous systems interfaces, content analysis, rule engine, workflow engine and so on.after then, discussion about them are provided.

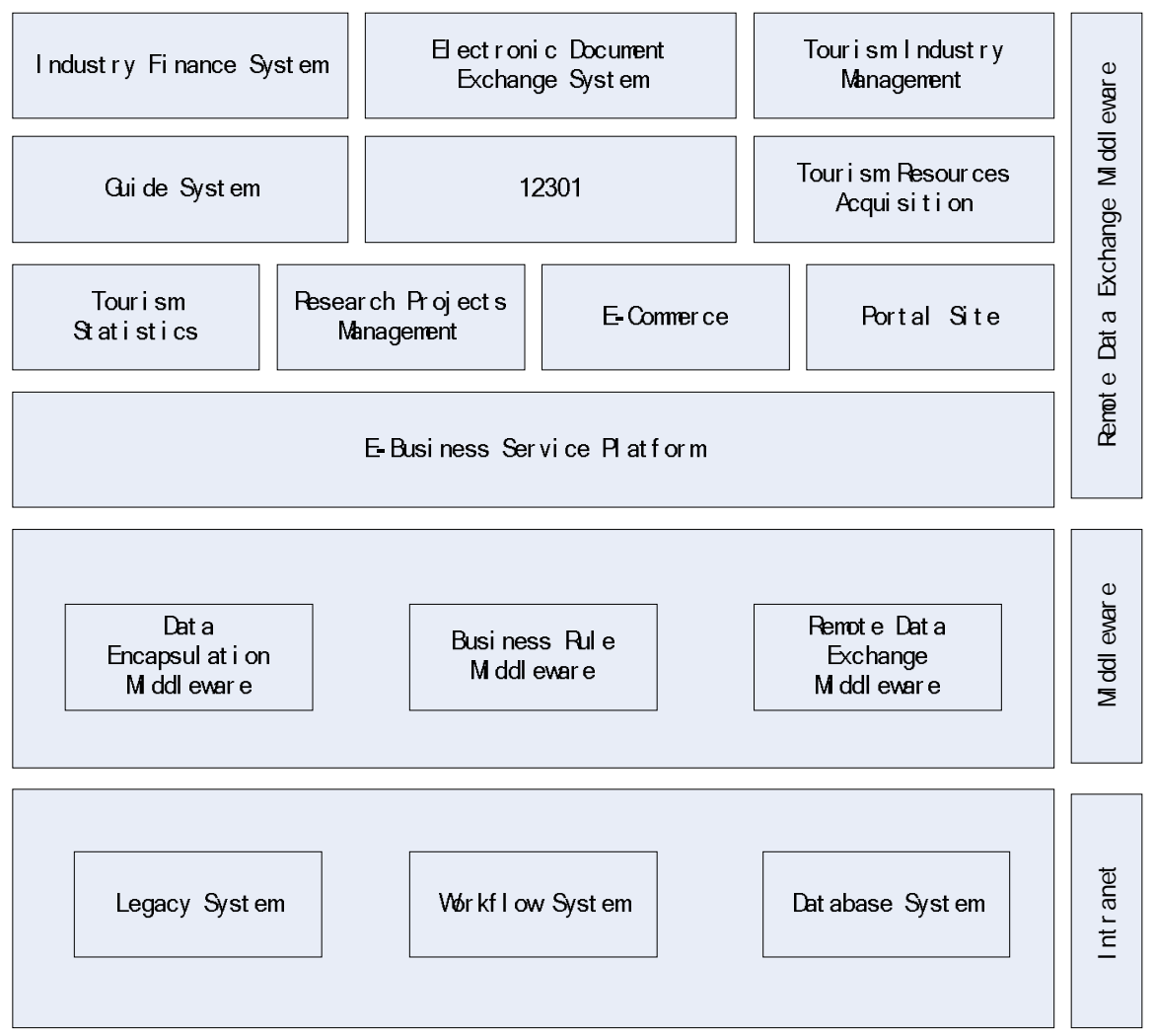

Fig.1 E-Business Service Platform

Integration of Digital Scenic Spot and Tourism Public Information Service

This integration framework is based on E-Business platform. It consists of intranet, middleware, and remote data exchange middleware etc. Intranet includes legacy system, workflow system and database system. Data encapsulation middleware, business rule middleware and remote data exchange middleware consists of the middleware parts. Remote data exchange middleware will connect the industry finance system, electronic document exchange system, tourism industry management, guide system, 12301 system, tourism resources acquisition, tourism statistics, research projects management, e-commerce and portal sites. This platform is supported by modern service industry common technology and tourism e-commerce common technology, and integrates the third-party service, tourism service chain heterogeneous systems and tourism business application systems by middleware technology. All these will reduce to one-stop tourism scenic spot e-business service center. 


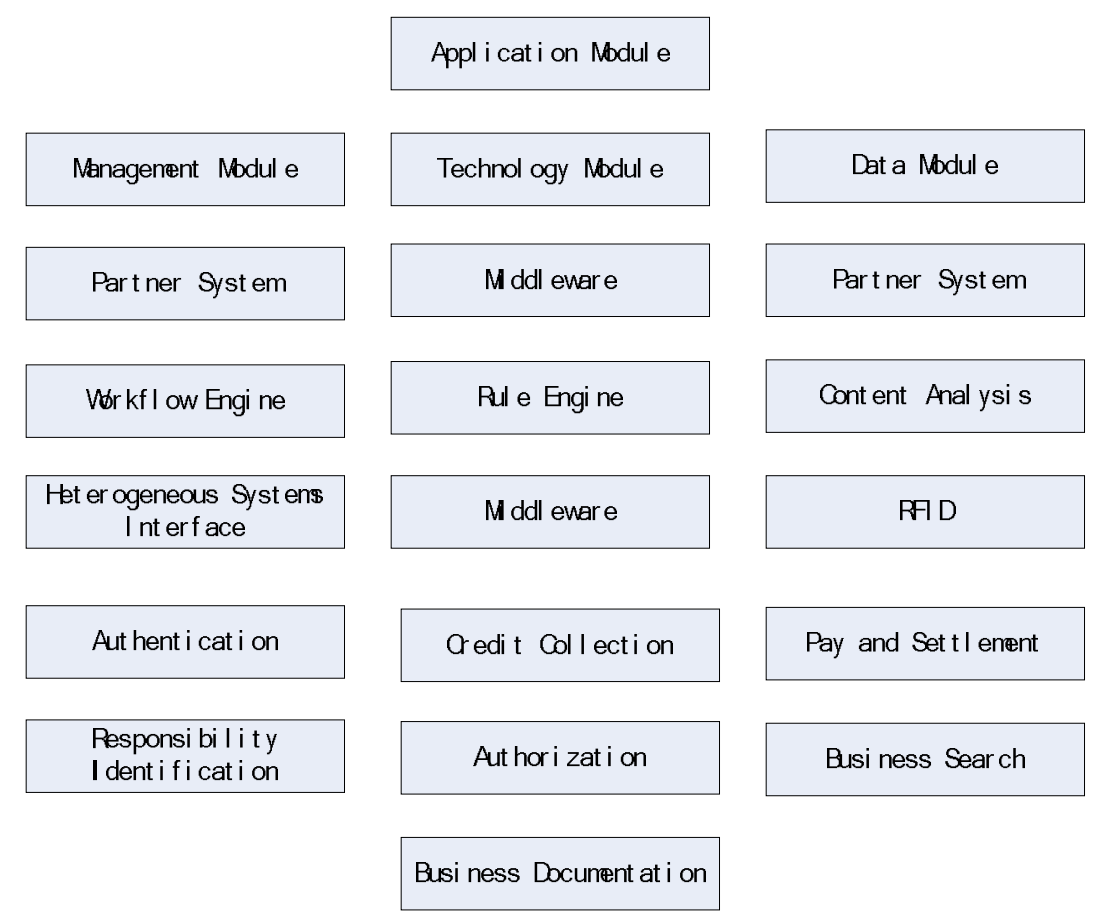

Fig.2 Technology Integration

It is important to realize the technology integration for the scenic spot e-business service system. It is shown as Fig. 2. These are many technologies used in tourism scenic spot such as business Documentation, business search, authorization, responsibility identification, pay and settlement, credit collection, authentication, RFID, middleware, Heterogeneous systems interfaces, content analysis, rule engine, workflow engine and so on. However, the partner systems should be interconnected by some technologies, some technologies should be selected for management module. In order to unify all the data format of different systems, and the data integration technologies need considering in advance. Application module will finish the work of combination of various application systems.

The construction of consumer tourism service infrastructure, by the application research of regional island-type service pattern, design by all-round service pattern, the task will be shared by relative government departments, tourism e-business/service operators, tourism scenic spots the construction of digital scenic spots and tourism public information service, and aids to the procedure of 'before travel,on travel and after travel' of tourists' travel for the developing of tourism personalised products and policy service. Tourists on travel service infrastructure, online credit investigation tourism e-business credit, and service trace tracking, to safeguard the service quality and travel experience of the all-round travel of tourist.

Digital scenic spot and tourism public information service includes e-ticket based on ID identification, advanced payment, tourism consumption , tourism insurance, One Card solution , and relative infrastructure construction, scenic spot automatic voice guide and service, scenic spot 
travelers flow monitoring device and service, scenic environment monitoring devices scene-remote data exchange transportation complement devices construction.

Travelers on journey service infrastructure construction, and it supplies the consultancy service, LBS and tour guide, route optimization and service quality complaint, scenic spot environment monitoring service, emergency event response and service.

Tourism e-business credit hierarchy system and service retrospect review based online credit investigator is online evaluation service of various tourism products and tourism services experienced by consumers after travel, traced by tourism e-business service platform operators and tourism government in order to improve the service quality of tourism suppliers.

\section{Conclusions}

Most tourism scenic spots' IT level is in the stage of Stage III - Control And Stage IV Integration in Nolan model, and their managers sense that it is crucial to make the data integrate and share the information in the big data era[9,10]. The E-Business Service Platform is proposed. It consists of three layers: intranet, middleware, remote data exchange middleware. The intranet will make the legacy system, workflow system and database system together, and the data could flow among them barrier freely. The middleware contains data encapsulation, business rule and remote data exchange middleware, to do the job of union of these parts. Remote data exchange middleware is responsible for the data going in the business systems such as industry finance system, electronic document exchange system, tourism industry management system, guide system, 12301, tourism resources acquisition system, tourism statistics, research projects management, e-commerce and portal sites[11]. On the other hand, the technology integration is also discussed in the study. Each business units should consider the responsibility identification, authorization, business search, business documentation, credit collection, pay and settlement, authentication synchronously. The technology of integration should also impel the application module, data module, management module, partner system, heterogeneous systems interface, content analysis to work coordinately.

\section{Acknowledgments}

This work was supported by the project of National Science Fund of P. R. China (under No. 71061005 and 71361007), the project of Hainan Provincial Science Fund (under No. 714263), the Project of Technology Department of Hainan Province of China (under No. SF201324) and Hainan University research funding HDSF201310.

\section{References}

[1] Nonna, Richard. "Managing The Crisis In Data Processing". Harvard Business Review 57 (2): 115-126.

[2] Nolan, Richard (1973). "Managing The Computer Resource: A Stage Hypothesis". Communications of the ACM 16 (4): 399-405.

[3] Gottschalk, Petter (2002). "Toward a Model of Growth Stages for Knowledge Management Technology in Law Firms". Informing Science 5 (2): 81-93.

[4] Kokkinou, Alinda, and David A. Cranage. "Using self-service technology to reduce customer waiting times." International Journal of Hospitality Management 33 (2013): 435-445.

[5] Xiangxiang Xie, Tao Hu, Baohong Li, Kaihua Huang. Research on the pattern of tourism 
e-commerce, 26th IEEE International Parallel \& Distributed Processing Symposium ( EI :

$20124215581242), 2012.5$

[6] Kokkinou, Alinda, and David A. Cranage. "Using self-service technology to reduce customer waiting times." International Journal of Hospitality Management 33 (2013): 435-445.

[7] Kasahara, Hidekazu, et al. "Business Model of Mobile Service for Ensuring Students' Safety Both in Disaster and Non-disaster Situations During School Trips." Information and Communication Technologies in Tourism 2014. Springer International Publishing, 2013. 101-114.

[8] Tao Hu, Baohong Li, Linfeng Dong. "A workflow coordination model for mobile agents based on role and task" , IEEE SMC2004, 2004.10.

[9] Tao Hu, Minyi Guo, Song Guo. "Quantitative Analysis of MTTF of Composite Web Services", Journal of the Chinese Institute of Engineers, 2013.7.

[10] Sparks, Beverley A., and Victoria Browning. "The impact of online reviews on hotel booking intentions and perception of trust." Tourism Management 32.6 (2011): 1310-1323.

[11] Tussyadiah, Iis P., and Florian J. Zach. "The role of geo-based technology in place experiences." Annals of Tourism Research 39.2 (2012): 780-800. 